\title{
ON THE MEASUREMENT OF CAPACITY UTILISATION AND COST EFFICIENCY: A NON-PARAMETRIC APPROACH AT FIRM LEVEL
}

\author{
Diego Prior * \\ Business Department \\ Universitat Autònoma de Barcelona \\ Spain \\ E-mail: diego.prior@uab.es
}

\section{Nela Filimon}

Economics Department

Universitat de Girona

Spain

* Corresponding author/autor para quem as correspondências devem ser encaminhadas

Received August 2001; accepted October 2002 after one revision.

\begin{abstract}
In this paper we evaluate the inefficiency generated by an inadequate structure of the fixed inputs and by the difficulty to adjust them in the short-run in a sample of Romanian firms in the chemical industry over the period 1996-1997. We use Data Envelopment Analysis (DEA) and apply this methodology in an innovative setting using a cost analysis instead of the technical efficiency approach. The results show inefficiency in most of the cases due to a low degree of capacity utilisation.
\end{abstract}

Keywords: capacity utilisation, DEA, cost efficiency. 


\section{Introduction}

The concept of capacity utilisation (CU) has been largely analysed in the economic literature from various perspectives, both theoretically and empirically, and has been very often used to explain changes in macroeconomic indicators like inflation rate or labour productivity. Many alternative CU measures have also been defined, but due to interpretation problems it doesn't exist an unanimous acceptance as to the most appropriate way of defining and measuring CU. In the present paper, we approach the notion of CU from the perspective offered by the economic theory of the firm, as a short-run concept depending on the level of fixed inputs of a firm.

In general, firms face difficulties in adjusting the fixed factors' endowments and this generates differences in the degree of capacity utilisation or in other words, inefficiency. Many times, the ability to adjust the fixed inputs - generating the so-called structural inefficiency - could be somehow slowed down by the presence of other factors like i.e.: adjustment costs, administrative regulations, external factors or measures of rationalisation, etc.

Our main purpose is to present a method of how to quantify cost inefficiency generated by the structural factors, in our case the impossibility in the short-run for the complete adjustment of the fixed (or quasi-fixed) inputs. This lack of adjustment, or better said the incapacity of firms to control for all fixed inputs' variations in the short-run, generates differences in the rate of capacity utilisation.

The paper was inspired by a previous work done by Prior (2002) where the author applies a similar methodology to the analysis of a sample of Spanish saving banks. Here, we use for the empirical application a sample of Romanian firms of the chemical industry over the period 1996-1997, classified in three digits groups. We present for every group - in average terms - the degree of utilisation for the fixed inputs in the short-run (CU), and the coefficients of cost efficiency in the long-run, short-run, and structural efficiency.

This analysis is developed within the framework of non-parametric (linear programming) frontier evaluation known as Data Envelopment Analysis (DEA) in which a measure of capacity utilisation is determined from data on observed inputs and outputs. Many times the concept of capacity is closely related to the technological characteristics of the production process. For this reason, DEA has the great advantage that it doesn't require any a priori specification about a particular functional form and this ensures the sufficient flexibility to adapt to the specific characteristics of the observed unit.

More about this and the most used definitions of CU and about the implications of the notion of optimal level of output from the perspective of production functions' theory, in the next section. In sections 2 and 3 we explain the models, in section 4 we present the data, in section 5 the results, and in section 6 we conclude.

\section{Brief Review of the Literature on Capacity Utilisation}

One of the most used definitions of CU rate is as the ratio of actual output to the potential output. Concerning the potential output, there are several ways to define it. One is the engineering or technical approach according to which potential output represents the maximum amount of output that can be produced in the short-run with the existent stock of capital (see Nelson, 1989, p.273). A similar discussion can be found in Johansen (1968, see Färe, Grosskopf \& Kokkelenberg, 1989, p.655), where the author defines the capacity as being: 
«... the maximum amount that can be produced per unit of time with existing plant and equipment, provided that the availability of variable factors of production is not restricted.»

Following this last definition, in one of his papers Färe (1984) describes the necessary and sufficient conditions for the existence of plant capacity as defined by Johansen. In a similar fashion, Färe, Grosskopf \& Kokkelenberg (1989) developed measures of plant capacity, plant capacity utilisation and technical change in the short-run for multi-product firms, based on frontier models using non-parametric linear programming methods (DEA).

The economic approach, on the other hand, defines the potential output as being the optimum level of output from the economic point of view. This alternative considers capital as a quasifixed input, and allows for distinction between short- and long-run cost curves. In the longrun, capital can be adjusted in order to achieve optimal (cost-minimising, profit-maximising) level. In the short-run capital is fixed and only the variable inputs can be varied. The shortrun equilibrium output, for a competitive firm, is then given by the equality between exogenous output price and the short-run marginal cost curve (SRMC), $Y^{*}$. The potential output would correspond to that level of output at which short-run average total cost (SRATC) is minimised $-Y^{* *}-$ (and equal to long-run average total cost, LRATC).

The definition of output as $Y^{* *}$ corresponds to the cost-minimisation problem while $Y^{*}$ corresponds to profit-maximisation. As pointed out in Berndt, Hesse \& Morrison (1981), this difference can affect short-run equilibrium in the sense that it may or may not occur at the level of output were the SRATC reaches its minimum: $Y^{*}>Y^{* *}$ or $\left(Y^{*}<Y^{* *}\right)$ when the output price is greater than (lower than) the minimum level of the SRATC. The authors address also the issue of how variations in input prices might affect the minimum point of the SRATC and hence $Y^{* *}$.

This economic approach was first analysed by Cassels (1937) and latter on two more definitions have been introduced. The first was suggested by Klein (1960) and Friedman (1963) and more recently by Segerson \& Squires (1990) who define the potential output as being the output level at which the long-run and short-run average total cost curves are tangent. The second approach supported by Cassels (1937) and Hickman (1964) takes as reference the output level at which the short-run average total cost curve reaches its minimum. The relationship between the two economic measures of CU depends upon the degree of scale economies for the unit that is being analysed. Berndt \& Hesse (1986) advocate that under the assumption of prevailing constant returns to scale in the long-run, the tangency point between the long-run and short-run curves will coincide with the point where the long-run and short-run average total cost curves reach their minimum. Hence the two economic measures of CU would be equivalent. Nelson (1989, p.274), using data from a sample of US privately owned electric utilities reaches the conclusion that: «The choice of a particular measure of CU may be of little consequence if all of the measures are highly correlated, and if the correlation is constant over time and across firms. If this is not the case, however, the choice may influence the conclusions to be drawn from a study.»

\section{Modelling Cost Efficiency in the Short and Long-Run}

Any of the definitions of capacity given above is more or less valid depending on the specific technological characteristics of the production process in question. This is the reason why, whatever the method used to evaluate cost efficiency, this method should be sufficiently 
flexible in order to adjust without restrictions to the characteristics of the unit or firm analysed. Before developing the model it is worthwhile to mention that as we try to determine the cost efficiency level it is fundamental the distinction between fixed and variable inputs.

\section{Model 1}

The notation we shall introduce here will be valid for the rest of the paper. Let's assume we have $k$ decision making units (DMUs) - firms in our case - to evaluate $(j=1, \ldots, k)$. The variables we need are the following: the input vector $x=\left(x_{1}, \ldots, x_{n}\right) \in R_{+}^{n}$, the output vector $y=\left(y_{1}, \ldots, y_{m}\right) \in R_{+}^{m}$ and the technology that describes the transformation of inputs into outputs as given below:

$$
F(y)=\{x:(y, x) \text { possible }\}
$$

We classify the inputs into fixed $\left(x_{f}\right)$, the inputs which do not allow for adjustment in the short-run, but available at increasing marginal costs in the long-run, and variable $\left(x_{v}\right)$, the inputs which are totally controlled by the firm in the short-run. The correspondent price vectors are: $\omega_{v}$ for the variable inputs, $\omega_{f}$ for the fixed inputs, and $P$, the output price vector. The typical optimisation problem faced by the firm is that of maximising variable profits (revenues minus variable costs) conditional on output price $(P)$, prices of the variable inputs $\omega_{v}$ and fixed inputs, $x_{f}$. An alternative framework, which we follow in this paper, is to solve the dual optimisation problem: minimisation of variable costs conditional on $Y, \omega_{v}$, and $x_{f}$. Under certain regularity conditions, for the production possibilities set in (1) it exists a short-run dual variable cost function which, will be given by:

$$
V C\left(\omega_{v}, y, x_{f}\right)=\min _{x_{v}}\left\{\omega_{v} \cdot x_{v} /\left(x_{v}, x_{f}\right) \in F(y)\right\}
$$

For the empirical application, we shall be working with three inputs: (1) material expenses, (2) labour and (3) capital. Inputs (1) and (2) are defined as variables in the short-run while input (3) is quasi-fixed. In the long-run all inputs can be varied. We don't have specific information about the prices of inputs for every firm. For this reason, in the short-run our vector $\omega_{v}$, will consist of: a unit vector, for the input (1) already in monetary terms, and wages for the second input. In the long-run, $\omega_{v}$ will include also as price for the capital input, the annual interest rate on money $(i \%)$ and the depreciation cost of capital $(\delta \%)$. The price vector for the fixed input (capital in the short-run), $\omega_{f}$, will consist of a unit vector as capital is already expressed in monetary terms. If we sum-up the cost of fixed inputs to expression (2) above, we obtain the short-run total cost function (SRTC):

$$
S R T C=V C\left(\omega_{v}, y, x_{f}\right)+\omega_{f} \cdot x_{f}
$$

Relation (3) above represents in fact the tangency condition between the short-run and longrun total cost curves. If $x_{f}^{*}$ represents the optimal value of fixed inputs, which minimises SRTC, then

$$
\left(\frac{\partial S R T C}{\partial x_{f}}\right)_{x_{f}=x_{f}^{*}}=\left(\frac{\partial V C}{\partial x_{f}}\right)_{x_{f}=x_{f}^{*}}+\omega_{f}=0
$$


at $x_{f}=x_{f}^{*}$. Equation (4) actually implies that, in long-run equilibrium, the reduction in variable costs from the last unit of fixed inputs just equals the price of fixed inputs. Solving equation (4) with respect to $x_{f}$ and substituting the result into equation (3) yields the longrun total cost function $($ LRTC):

$$
\operatorname{LRTC}=\operatorname{LRTC}\left(\omega_{v}, \omega_{f} ; y\right)
$$

Equation (5) would correspond to the dual of the production set if the firm were to minimise its total cost. In fact, $S R T C=L R T C$ if and only if $x_{f}=x_{f}^{*}$. When different, SRTC is always larger than LRTC. Another way of putting it is that SRTC and LRTC are tangent at $x_{f}=x_{f}^{*}$. Resuming, SRTC is an accepted representation of the technology even if $x_{f} \neq x_{f}^{*}$ whereas LRTC is valid only when $x_{f}=x_{f}^{*}$. The outcomes of this process are first the $V C$, and second the optimal values for the fixed inputs $x_{f}^{*}$. All together represent in fact the long-run equilibrium for a given firm. Knowing the real and optimal values for inputs $(x), S R T C$ and $L R T C$, we can measure the distance between the two levels of fixed inputs (optimal and real) and determine this way the rate of utilisation with respect to the economical optimum:

$$
\frac{x_{f}^{*}}{x_{f}} \leq>1
$$

The associated structural efficiency will be given by:

$$
0 \leq \frac{\operatorname{LRTC}\left(\omega_{v}, \omega_{f} ; y\right)}{V C\left(\omega_{v}, y, x_{f}\right)+\omega_{f} \cdot x_{f}} \leq 1
$$

\section{The Measurement of Frontier Efficiency in the Short- and Long-Run, and the Determination of Structural Efficiency}

The model described above represents the usual cost minimisation problem and is only the first step for the evaluation of the rate of utilisation for the fixed inputs. So, taking as a starting point relation (1), and given a matrix of outputs $(Y)$ of order $k x m$, a matrix of fixed inputs $\left(X_{f}\right)$ of order $k x n_{l}$, and a matrix of variable inputs $\left(X_{v}\right)$ of order $k x n_{2}\left(n_{l}+n_{2}=n\right)$, we can define, for every $D M U_{j}$, a production possibilities set $F\left(y_{j}\right)$ as a linear combination of the matrices described above:

$$
F\left(y_{j}\right)=\left\{x_{j}: z \cdot Y \geq y_{j}, x_{f j} \geq z \cdot X_{f}, x_{v j} \geq z \cdot X_{v}, z \in R_{+}^{k}\right\}
$$

where $z=\left(z_{1}, z_{2}, \ldots, z_{k}\right)$ is the intensity vector $(\mathrm{z} \geq 0)$. Assuming as known the prices of inputs $\left(\omega_{v}, \omega_{f} \geq 0\right)$ then it is possible to compute variable cost $\left[\omega_{v} \cdot x_{v}\right]$ and total cost $\left\lfloor\omega_{v} \cdot x_{v}+\omega_{f} \cdot x_{f}\right\rfloor$ for every firm in the sample. 


\section{Model 2}

Once calculated variable, fixed and total costs we could define a short-run measure for the frontier efficiency (SRE) as being the coefficient between the minimum short-run total cost $\left[V C\left(\omega_{v}, y, x_{f}\right)+\omega_{f} \cdot x_{f}\right]$ and the total cost of the firm to be analysed $\left[\omega_{v} \cdot x_{v}+\omega_{f} \cdot x_{f}\right]$ :

$$
\operatorname{SRE}\left(\omega_{v}, y, x_{v}, x_{f}\right)=\frac{V C\left(\omega_{v}, y, x_{f}\right)+\omega_{f} \cdot x_{f}}{\omega_{v} \cdot x_{v}+\omega_{f} \cdot x_{f}}
$$

The short-run variable cost $(V C)$ is the optimal solution of the following minimisation programme:

$$
\begin{array}{ll} 
& V C\left(\omega_{v}, y, x_{f}\right)=\min \left(\omega_{v} \cdot x_{v}^{*}\right) \\
\text { s.t. }: & z \cdot Y \geq y \\
& x_{v}^{*} \geq z \cdot X_{v} \\
& x_{f}=z \cdot X_{f} \\
& \sum_{j=1}^{k} z_{j}=1
\end{array}
$$

$$
\text { and } 0 \leq S R E \leq 1
$$

A value of $S R E=1$, implies that the firm in question is performing in the short-run in the efficient cost frontier while a value of $S R E<1$ will indicate us that the firm is not in the efficient short-run cost frontier. Then the difference $[1-S R E]$ will give the magnitude of the reduction in costs that would locate the firm in the efficient cost frontier.

The result of the optimisation programme [10] is illustrated graphically in the Figures 1a and $1 \mathrm{~b}$ below. In Figure 1a we present the average cost minimisation approach. In Figure 1b we give the equivalent situation but in a variable input set.

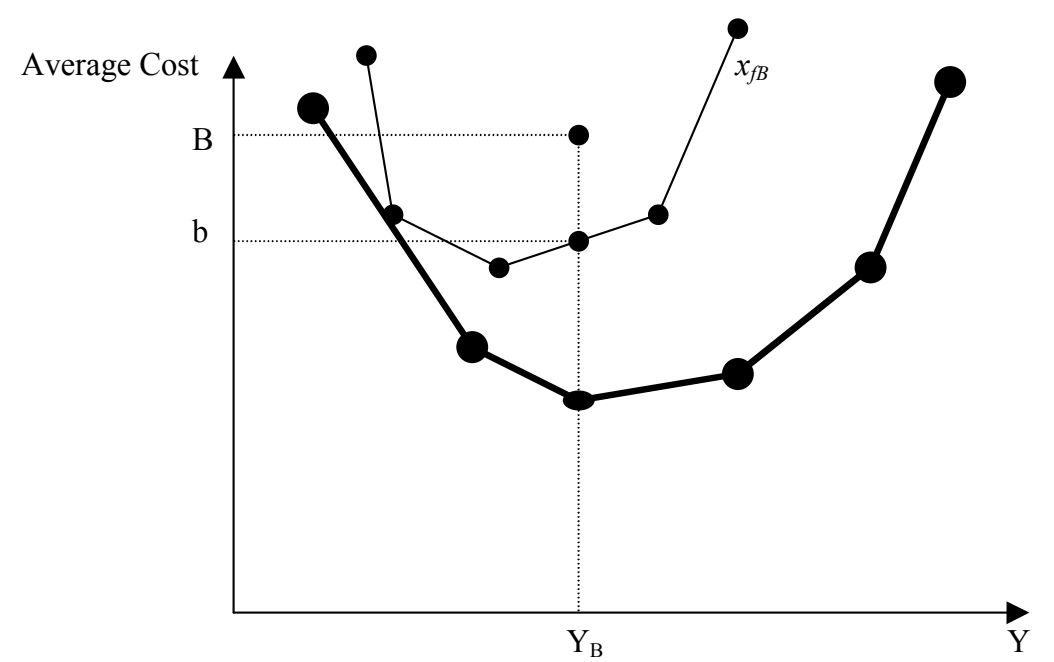

Figure 1a - Short-Run Cost Efficiency - Average Cost Minimisation Approach 
Assuming that it is not possible to adjust for the fixed inputs, after applying programme [10] we obtain point $b$ and from the graph in Figure 1a it can be seen that point $\mathrm{B}$ (the observed average cost) is inefficient with respect to the short-run cost efficiency frontier (point b).

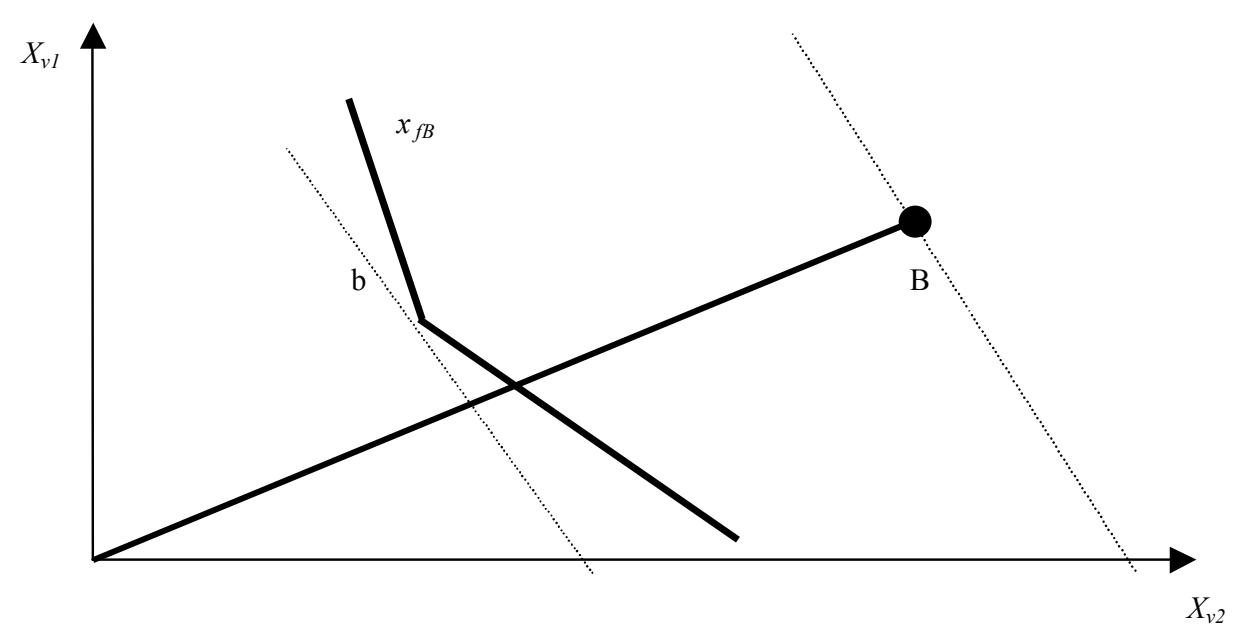

Figure 1b - Short-Run Cost Efficiency - Variable Inputs Orientation Approach

Expression [10.1] presents the formalisation corresponding to points $(\mathrm{B}, \mathrm{b})$ in Figures 1a and $1 \mathrm{~b}$ with two variable inputs and one fixed input.

$$
\begin{aligned}
& B=\omega_{v 1} \cdot x_{v 1}^{B}+\omega_{v 2} \cdot x_{v 2}^{B}+\omega_{f} \cdot x_{f}^{B} \\
& b=\omega_{v 1} \cdot x_{v 1}^{*}+\omega_{v 2} \cdot x_{v 2}^{*}+\omega_{f} \cdot x_{f}^{B} \\
& \operatorname{SRE}\left(\omega_{v}, \omega_{f}, y, x_{v}, x_{f}\right)=\frac{b}{B}<1
\end{aligned}
$$

In a similar manner we can compute the efficient cost frontier in the long-run (LRE) the only difference being given by the fact that now it is possible to adjust for the fixed inputs.

$$
\operatorname{LRE}\left(\omega_{v}, \omega_{f}, y, x_{v}, x_{f}\right)=\frac{\operatorname{LRTC}\left(\omega_{v}, \omega_{f} ; y\right)}{\omega_{v} x_{v}+\omega_{f} x_{f}}
$$

The numerator of expression (11) - the long-run total cost (LRTC) - will be given by the following minimisation programme:

$$
\begin{aligned}
& \operatorname{LRTC}\left(w_{v}, w_{f} ; y\right)=\min \left(w_{v} \cdot x_{v}^{*}+w_{f} \cdot x_{f}^{*}\right) \\
& \begin{array}{c}
\text { s.t. }: \quad z \cdot Y \geq y \\
x_{i}^{*} \geq z \cdot X_{i} \quad i=\underbrace{1, \ldots, v \text { fixed inputs }}_{\text {variable }}, v+1, \ldots, F \\
\quad \sum_{j=1}^{k} z_{j}=1
\end{array}
\end{aligned}
$$


The graphical result of the optimisation programme [12] can be seen in Figures $2 \mathrm{a}$ and $2 \mathrm{~b}$. In a setting similar to the one defined for figures $1 \mathrm{a}$ and $1 \mathrm{~b}$, the programme evaluates the longrun cost efficiency frontier (LRCEF) represented by point $\mathrm{D}$.

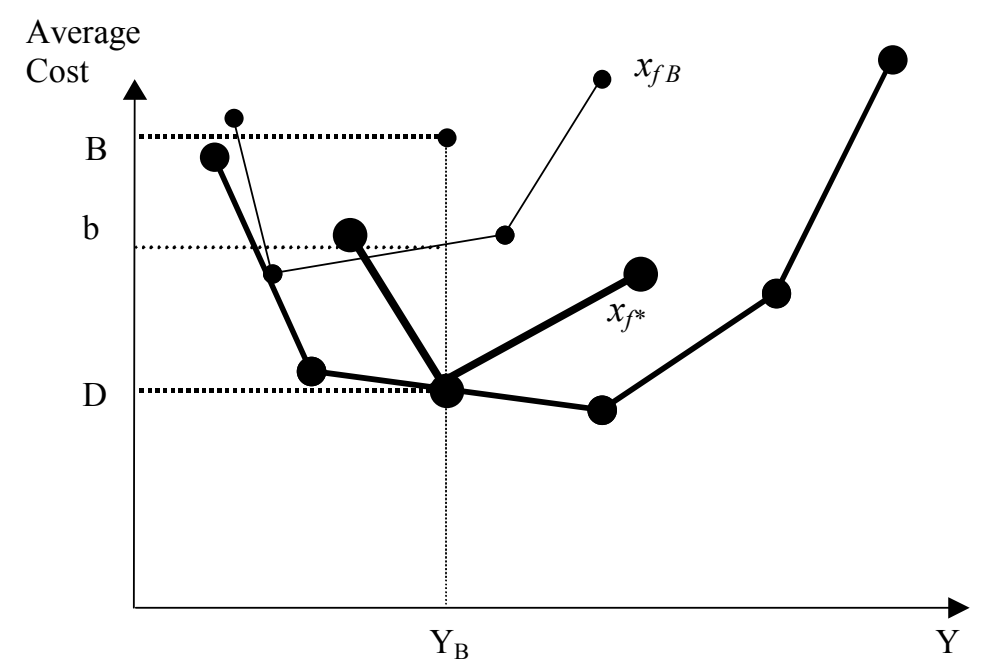

Figure 2a - Long-Run Cost Efficiency - Average Cost Minimisation Approach

In the long-run we allow for adjustment of all fixed and variable inputs and point D is feasible. In Figure $2 b$ we present the equivalent situation but in a variable input set. In contrast with the results presented in Figures $1 \mathrm{a}$ and $1 \mathrm{~b}$, we see now how adjusting fixed inputs a lower cost can be obtained $(\mathrm{D}<\mathrm{b})$.

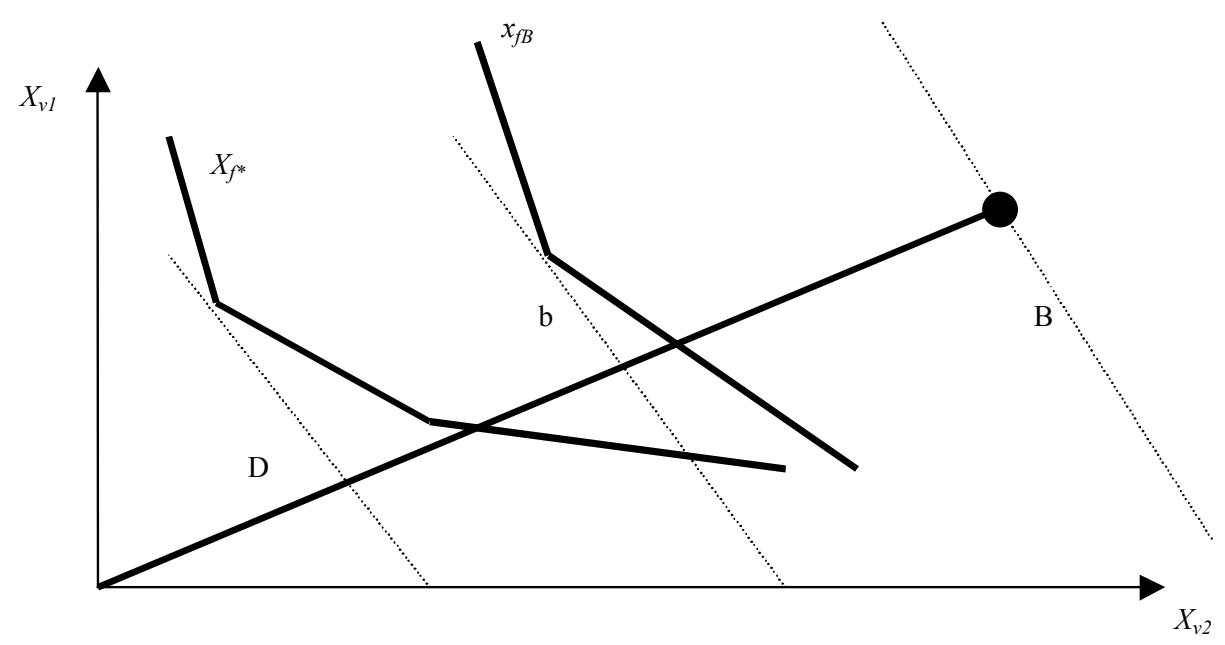

Figure 2b - Long-Run Cost Efficiency - Variable Inputs Orientation Approach 
Expression [12.1] gives the formalisation corresponding to points B and D for the particular case of two variable inputs and one fixed input.

$$
\begin{aligned}
& B=\omega_{v 1} \cdot x_{v 1}^{B}+\omega_{v 2} \cdot x_{v 2}^{B}+\omega_{f} \cdot x_{f}^{B} \\
& D=\omega_{v 1} \cdot x_{v 1}^{*}+\omega_{v 2} \cdot x_{v 2}^{*}+\omega_{f} \cdot x_{f}^{*} \\
& \operatorname{LRE}\left(\omega_{v}, \omega_{f}, y, x_{v}, x_{f}\right)=\frac{D}{B}<1
\end{aligned}
$$

Once known SRE and LRE the next step is to compute structural efficiency (SE):

$$
0 \leq \frac{\operatorname{LRE}\left(\omega_{v}, \omega_{f}, y, x_{v}, x_{f}\right)}{\operatorname{SRE}\left(\omega_{v}, y, x_{v}, x_{f}\right)} \leq 1
$$

In particular, for the case illustrated in Figures $1 \mathrm{a}, 1 \mathrm{~b}$ and $2 \mathrm{a}, 2 \mathrm{~b}$ if combine the SRE and LRE variables defined in expressions [10.1] and [12.1], $S E$ is given by the following relation:

$$
S E=\frac{L R E}{S R E}=\frac{D}{b}<1
$$

Finally, the degree of capacity utilisation for the fixed inputs $(C U)$ in the short-run will be given by the expression below where, $x_{f}^{*}$ stands for the required level of fixed inputs in order to minimise long-run total costs:

$$
C U=\frac{x_{f}^{*}}{x_{f}} \leq>1
$$

A value of $C U=1$ will indicate that the actual physical capital (fixed inputs) corresponds to the long-run equilibrium level. If $C U$ is significantly different from unity then the maintained level of fixed inputs doesn't minimise the total costs: (1) $C U<1$ will represent an excess of fixed inputs (under-utilisation of fixed inputs), and (2) $C U>1$ will reflect the fact that there is an over-utilisation of the fixed inputs. In particular, for the case presented in Figures 1a and $1 \mathrm{~b}, C U=\frac{x_{f}^{*}}{x_{f}^{B}}>1$ which means over-utilisation.

\section{About the Data}

For the empirical application we worked with data on a survey of 96 firms in the Romanian chemical industry over the period 1996-1997. The firms are organised in three groups according to the type of activity developed (3-digit level). The main objective was to achieve a higher degree of homogeneity among the firms whose performance is evaluated at a time. The groups are the following: varnishes and paints manufacturing (34); medicaments and pharmaceutical products manufacturing (31) and soaps, detergents, perfumes and cosmetics products manufacturing (31). We have individual firm balance sheet and profit and loss statement data on the variables presented in Table 1: 
Table 1 - Variables used in the analysis

\begin{tabular}{|l|l|l|l|}
\hline & \multicolumn{1}{|c|}{ Outputs } & \multicolumn{1}{c|}{ Fixed Costs } & \multicolumn{1}{c|}{ Variable Costs } \\
\hline Short-Run & Turnover & Cost of fixed assets & $\begin{array}{l}\text { Costs with the personnel } \\
\text { Material expenses }\end{array}$ \\
\hline Long-Run & Turnover & & $\begin{array}{l}\text { Costs with the personnel } \\
\text { Material expenses } \\
\text { Cost of fixed assets }\end{array}$ \\
\hline
\end{tabular}

The original data were expressed in thousands of Lei in current prices. The data finally used for analysis are expressed in thousands of Lei and constant prices for 1996. We made use of annual price indices (National Commission for Statistics, Price Statistical Bulletin, vol. 8/7, 1997) for the chemical industry reported by the statistics office. For the adjustment of capital input in the long-run we used the interest rate on money (i) (we used the annual interest rate on money reported by EximBank, Romania - Main macroeconomic indicators - Buletin Trimestral, no. 1/1998), and the depreciation cost of capital ( $\delta$ ). The interest rate on money in 1996, was of $35 \%$ while in 1997 raised up to $47.2 \%$. We applied these values without discrimination to all groups of firms as it was the best substitute available for the cost of capital - at firm level - we disposed of. The depreciation cost of capital $(\delta)$ was calculated with accounting methods as percentage of depreciation in total fixed assets (tangible + intangible), all expressed in monetary terms. From $\delta$ calculated at firm level, we determined an average $\delta$ for every group and apply $(i+\delta)$ to adjust long-run fixed assets.

Some observations were discarded because some data were missing for one or both years, or for some of the variables. Other observations were identified as outliers. Wilson (1995, p.27-28) speaks about influential observations when referring to outliers and defines them as «those sample observations which play a relatively large role in determining estimated efficiency scores for at least some other observations in the observed sample.»

The technique we use to identify outliers is the one proposed by Andersen \& Petersen (1993). With a radial distance we calculate superefficiency scores. For the inefficient observations, the superefficiency coincides with the standard score, while for the efficient observations a score is computed which indicates the maximal radial change which is feasible such that the observation remains efficient. We finally decided to remove all the outliers from the sample as we had no other independent source of information available in order to examine and correct the data. In Table 2 we present for every group and year basic statistics for input and output variables: mean, standard deviation, minimum and maximum values. 
Prior \& Filimon - On the measurement of capacity utilisation and cost efficiency: a non-parametric approach at firm level

Table 2 - Descriptive Statistics of the Sample of Observations

\begin{tabular}{|c|c|c|c|c|c|}
\hline & & Turnover & $\begin{array}{c}\text { Cost of Material } \\
\text { Expenses }\end{array}$ & $\begin{array}{l}\text { Number of } \\
\text { Employees }\end{array}$ & $\begin{array}{l}\text { Cost of } \\
\text { Capital }\end{array}$ \\
\hline Group 1 & \multicolumn{5}{|c|}{ Varnishes and Paints Manufacturing } \\
\hline \multirow[t]{4}{*}{1996} & Mean Value & 9233.26 & 5818.19 & 133 & 3579.62 \\
\hline & Std. Deviation & 22924.15 & 15302.15 & 360 & 10903.63 \\
\hline & Max. Value & 125582.78 & 83338.25 & 1743 & 48788.42 \\
\hline & Min. Value & 78.48 & 2.84 & 9 & 11.32 \\
\hline \multirow[t]{4}{*}{1997} & Mean Value & 15703.60 & 9639.68 & 128 & 3644.19 \\
\hline & Std. Deviation & 38504.57 & 25321.30 & 341 & 10019.75 \\
\hline & Max. Value & 209198.08 & 133879.93 & 1681 & 47776.25 \\
\hline & Min. Value & 218.6 & 73.21 & 10 & 9.52 \\
\hline Group 2 & \multicolumn{5}{|c|}{ Medicaments and Pharmaceutical Products Manufacturing } \\
\hline \multirow[t]{4}{*}{1996} & Mean Value & 20971.89 & 12109.26 & 345 & 9813.60 \\
\hline & Std. Deviation & 38042.92 & 25458.56 & 706 & 20947.24 \\
\hline & Max. Value & 148989.01 & 102788.88 & 2816 & 79728.91 \\
\hline & Min. Value & 200.08 & 4.47 & 9 & 1.76 \\
\hline \multirow[t]{4}{*}{1997} & Mean Value & 40418.23 & 20451.33 & 349 & 10369.30 \\
\hline & Std. Deviation & 74348.40 & 42112.98 & 686 & 21866.89 \\
\hline & Max. Value & 280325.08 & 166219.03 & 2737 & 84626.39 \\
\hline & Min. Value & 334.98 & 9.47 & 11 & 1.09 \\
\hline Group 3 & \multicolumn{5}{|c|}{ Soaps, Detergents, Perfumes and Cosmetics Products Manufacturing } \\
\hline \multirow[t]{4}{*}{1996} & Mean Value & 10851.55 & 4547.49 & 123 & 4338.98 \\
\hline & Std. Deviation & 27389.58 & 9102.23 & 233 & 8920.83 \\
\hline & Max. Value & 148809.56 & 43814.04 & 1011 & 33955.92 \\
\hline & Min. Value & 416.12 & 41.31 & 9 & 4.41 \\
\hline \multirow[t]{4}{*}{1997} & Mean Value & 21841.67 & 10168.10 & 121 & 5378.99 \\
\hline & Std. Deviation & 48868.96 & 24985.71 & 209 & 12327.89 \\
\hline & Max. Value & 233045.23 & 103277.92 & 931 & 57965.67 \\
\hline & Min. Value & 571.81 & 375.06 & 9 & 5.48 \\
\hline
\end{tabular}

Note: Except for the number of employees, all the data are in Million Lei and constant prices 1996. 


\section{Empirical Results Obtained with the Proposed Evaluation}

We apply the DEA methodology - programmes [10] and [12] - in a variable returns to scale and input orientation setting given that we have a time horizon of only two years and due to the important differences in the size of the analysed firms, observed in Table 2 above. The results concerning CU are summarised in Table 3. For group 1, the general picture shows that, in average, in both years prevails a CU>1, (1.45 in 1996 and 1.05 in 1997) which means over-utilisation. In group 2, the bulk of the observations exhibit under-utilisation both in 1996 and $1997-\mathrm{CU}<1-(0.32$ vs. 0.43$)$. In group 3, on the contrary we have found overutilisation of the fixed inputs $-\mathrm{CU}>1$ in both years: 1.43 in 1996 and 1.28 in 1997. The number of units with CU $\geq 1$ varies from $68 \%$ in 1996 to $50 \%$ in 1997.

Table 3 - The Degree of Utilisation of the Fixed Inputs in the Short-Run (CU)

\begin{tabular}{|c|c|c|c|c|c|c|}
\hline \multirow[t]{2}{*}{ Indicators } & \multicolumn{2}{|c|}{$\begin{array}{c}\text { Group 1: } \\
\text { Varnishes and Paints } \\
\text { Manufacturing }\end{array}$} & \multicolumn{2}{|c|}{$\begin{array}{c}\text { Group 2: } \\
\text { Medicaments and } \\
\text { Pharmaceutical } \\
\text { Products } \\
\text { Manufacturing }\end{array}$} & \multicolumn{2}{|c|}{$\begin{array}{c}\text { Group 3: } \\
\text { Soaps, Detergents and } \\
\text { Cosmetics Products } \\
\text { Manufacturing }\end{array}$} \\
\hline & 1996 & 1997 & 1996 & 1997 & 1996 & 1997 \\
\hline Global Mean & 1.45 & 1.05 & 0.32 & 0.43 & 1.43 & 1.28 \\
\hline Standard Deviation & 1.21 & 0.73 & 0.35 & 0.39 & 1.01 & 1.18 \\
\hline Maximum Value & 4.30 & 3.28 & 1.00 & 1.12 & 3.40 & 4.28 \\
\hline Minimum Value & 0.03 & 0.07 & 0.02 & 0.04 & 0.12 & 0.11 \\
\hline \multicolumn{7}{|c|}{ Number of Units with: } \\
\hline $\mathrm{CU}<1$ & $7(25 \%)$ & $11(39 \%)$ & $26(87 \%)$ & $22(73 \%)$ & $9(32 \%)$ & $14(50 \%)$ \\
\hline $\mathrm{CU}=1$ & $10(36 \%)$ & $8(29 \%)$ & $4(13 \%)$ & $7(24 \%)$ & $7(25 \%)$ & $6(21 \%)$ \\
\hline $\mathrm{CU}>1$ & $11(39 \%)$ & $9(32 \%)$ & $0(0 \%)$ & $1(3 \%)$ & $12(43 \%)$ & $8(29 \%)$ \\
\hline Total No. of Units & 28 & 28 & 30 & 30 & 28 & 28 \\
\hline
\end{tabular}

We calculate also, for every group, the growth rate of sales and of fixed assets for 1996 and 1997, in constant prices 1996, and the results are given in Table 4. Concerning the growth rate of fixed assets, the intuition behind is the following: when CU>1 (over-utilisation), firms are in need of capacity that is to say there is incentive for investment in fixed assets. So, we would expect the growth rate of fixed assets when CU>1 to be greater than when $\mathrm{CU}<1$. If analyse the figures in Table 4 we can see that when compare groups 2 and 3 the results go in the same line with the intuition. When consider group 1 relative to group 2 the results go against the intuition. The other ratio we calculate, growth rate of sales, can be related with the CU in the following way: if consider an "U" - shaped average cost curve, when firms operate with $\mathrm{CU}<1$ (decreasing average cost), the more they produce and sell the lower the unitary cost. In contrast, when firms operate with $\mathrm{CU}>1$ (increasing average cost), more output would imply a higher unitary cost. The results in Table 4, support the intuition when look at group 2 relative to group 1 but, not for group 2 vs. group 3. 
Table 4 - Growth Rates of Fixed Assets (FA) and of Sales

\begin{tabular}{|c|c|c|}
\hline Groups & Growth Rate of Fa (\%) & Growth Rate of Sales (\%) \\
\hline $1(\mathrm{CU}>1)$ & 6.8 & 74.28 \\
\hline $2(\mathrm{CU}<1)$ & 9.0 & 87.14 \\
\hline $3(\mathrm{CU}>1)$ & 24.6 & 105 \\
\hline
\end{tabular}

The conclusion is that there is no clear-cut relationship between the percentage of FA, the percentage of sales and CU (over- and under-utilisation). In the sample of firms we are analysing the exact correspondence between physical capital and money value of accounting fixed assets is far to be achieved. It appears here the very well know problem related with the economic interpretation of accounting valuation rules. In our specific case study, this problem is probably amplified by the severe inflation rate and the unclear application of accounting principles as we didn't dispose of an audit report for any of the firms included in the survey. Table 5 exhibits statistical information on consumer price index for several East European countries, and some OECD Member countries. As it can be seen from the data, in Romania in 1996 and 1997, the inflation rate was particularly high.

Table 5 - Consumer Price Index ( $\%$ changes from previous year)

\begin{tabular}{|l|r|r|r|r|r|r|r|r|r|}
\hline \multicolumn{1}{|c|}{ Country } & $\mathbf{1 9 9 0}$ & $\mathbf{1 9 9 1}$ & $\mathbf{1 9 9 2}$ & $\mathbf{1 9 9 3}$ & $\mathbf{1 9 9 4}$ & $\mathbf{1 9 9 5}$ & $\mathbf{1 9 9 6}$ & $\mathbf{1 9 9 7}$ & $\mathbf{1 9 9 8}$ \\
\hline Bulgaria & 26.0 & 333.0 & 79.4 & 72.9 & 96.0 & 62.1 & 123.0 & 1083.0 & 22.2 \\
\hline Czech Republic & 26.0 & 56.8 & 11.1 & 20.8 & 10.0 & 9.1 & 8.8 & 8.5 & 10.6 \\
\hline Hungary & 28.4 & 34.8 & 23.2 & 22.5 & 18.9 & 28.3 & 23.5 & 18.3 & 14.3 \\
\hline Poland & 585.8 & 76.0 & 45.0 & 36.9 & 32.1 & 27.9 & 19.9 & 14.9 & 11.7 \\
\hline Romania & 5.1 & 174.0 & 210.4 & 256.1 & 136.8 & 32.3 & 38.8 & 154.9 & 59.3 \\
\hline France & 3.4 & 3.2 & 2.4 & 2.1 & 1.7 & 1.7 & 2.0 & 1.2 & 0.8 \\
\hline Netherlands & 2.5 & 3.2 & 3.2 & 2.6 & 2.8 & 1.9 & 2.0 & 2.2 & 2.0 \\
\hline Spain & 6.7 & 5.9 & 5.9 & 4.6 & 4.7 & 4.7 & 3.6 & 2.0 & 1.8 \\
\hline
\end{tabular}

Source: "Transition at a Glance", Centre for Co-operation with non-Members, CCNM/STD (2001)1, p.68.

With respect to the cost analysis the results are summarised in Table 6 and the situation is the following: in group 1, the short-run average level of cost efficiency (SRE) is below 1 (100\%) both in $1996(86 \%)$ and $1997(89 \%)$. As the maximum value that could be taken by this indicator is $1(100 \%)$, the difference [1-SRE] represents the reduction in costs that would locate the unit in the efficient cost frontier (that is to say the potential cost savings are, in average, of $14 \%$ and $11 \%$ ). In the long-run the cost efficiency measures (LRE) are relatively smaller than the ones in the short-run $(81 \% 1996,83 \%$ 1997) which imply a greater difference [1-LRE] on average (19\% and $17 \%$ respectively).

As a consequence of both measures of cost efficiency - in the short and long-run - being lower than $1(100 \%)$, most of the units exhibit, in average, structural inefficiency $(\mathrm{SE}<1)$, so they have costs excess due to an inadequate fixed factors endowment in the short-run. In 
1996 the level of structural efficiency was in average terms of about 93\% while in 1997 decreased to $92 \%$. More than half of the units exhibited a level of SE $=1(100 \%)$. In other words, the observed level of fixed inputs does not imply any inefficiency for these firms provided that it appears as being the optimal level for them. A similar picture is valid for the rest of the groups. The firms have cost excess due to the structure of the fixed inputs. Group 2 i.e. exhibits, in average, the highest levels of structural inefficiency (lowest SE), 64\% in 1996 and $70 \%$ in 1997.

Table 6 - Average Cost Efficiency Results

\begin{tabular}{|l|c|c|c|c|c|c|}
\hline \multicolumn{1}{|c|}{ Indicators } & \multicolumn{2}{|c|}{$\begin{array}{c}\text { Group 1: } \\
\text { Varnishes and Paints } \\
\text { Manufacturing } \\
\text { Medicaments and } \\
\text { Pharmaceutical } \\
\text { Products } \\
\text { Manufacturing }\end{array}$} & $\begin{array}{c}\text { Goaps, Detergents, } \\
\text { Perfumes and } \\
\text { Cosmetics Products } \\
\text { Manufacturing }\end{array}$ \\
\cline { 2 - 7 } & $\mathbf{1 9 9 6}$ & $\mathbf{1 9 9 7}$ & $\mathbf{1 9 9 6}$ & $\mathbf{1 9 9 7}$ & $\mathbf{1 9 9 6}$ & $\mathbf{1 9 9 7}$ \\
\hline $\begin{array}{l}\text { Long-Run Cost } \\
\text { Efficiency (LRE) }\end{array}$ & $81 \%$ & $83 \%$ & $49 \%$ & $56 \%$ & $79 \%$ & $75 \%$ \\
\hline Minimum Value & $38 \%$ & $35 \%$ & $6 \%$ & $7 \%$ & $39 \%$ & $17 \%$ \\
\hline LRE < 100 (No. Units) & $19(56 \%)$ & $19(56 \%)$ & $26(84 \%)$ & $22(71 \%)$ & $20(65 \%)$ & $21(68 \%)$ \\
\hline LRE =100 (No. Units) & $15(44 \%)$ & $15(44 \%)$ & $5(16 \%)$ & $9(29 \%)$ & $11(35 \%)$ & $10(32 \%)$ \\
\hline $\begin{array}{l}\text { Short-Run Cost } \\
\text { Efficiency (SRE) }\end{array}$ & $86 \%$ & $89 \%$ & $72 \%$ & $78 \%$ & $88 \%$ & $85 \%$ \\
\hline Minimum Value & $48 \%$ & $47 \%$ & $18 \%$ & $27 \%$ & $51 \%$ & $32 \%$ \\
\hline SRE < 100 (No. Units) & $18(53 \%)$ & $15(44 \%)$ & $19(61 \%)$ & $15(48 \%)$ & $15(48 \%)$ & $16(52 \%)$ \\
\hline SRE = 100 (No. Units) & $16(47 \%)$ & $19(56 \%)$ & $12(39 \%)$ & $16(52 \%)$ & $16(52 \%)$ & $15(48 \%)$ \\
\hline $\begin{array}{l}\text { Structural Efficiency } \\
\text { (SE) }\end{array}$ & $93 \%$ & $92 \%$ & $64 \%$ & $70 \%$ & $89 \%$ & $88 \%$ \\
\hline Minimum Value & $38 \%$ & $40 \%$ & $7 \%$ & $10 \%$ & $39 \%$ & $17 \%$ \\
\hline SE < 100 (No. Units) & $16(47 \%)$ & $14(41 \%)$ & $23(79 \%)$ & $21(72 \%)$ & $14(45 \%)$ & $17(55 \%)$ \\
\hline SE = 100 (No. Units) & $18(53 \%)$ & $20(59 \%)$ & $6(21 \%)$ & $8(30 \%)$ & $17(55 \%)$ & $14(45 \%)$ \\
\hline Total No. of Units & 34 & 34 & 29 & 29 & 31 & 31 \\
\hline
\end{tabular}

\section{Concluding Remarks}

This work is intended to have two main contributions. The first one is the proposal of cost inefficiency estimation, applied within a non-parametric setting. The differences in cost among firms could be explained considering mainly two approaches: analysing the size of the firms or the level of fixed inputs. In this paper we deal with the problem of fixed inputs and the capacity utilisation as influential factor, provided that the literature sorted out the first approach long ago. Nevertheless, observing the prevalent source of inefficiency of firms - size or the fixed inputs level - it is an interesting question to study, and we reserve it for a future extension of the present work. 
The second contribution relates to the empirical application in itself. Total Factor Productivity (TFP) is a standard measure widely used in many empirical studies concerning the well-established market economies but has not been used to a large extent in transition economies for which there is not that much work done on productivity analysis, in a nonparametric framework, in particular.

In average our findings show that in most of the cases the prevalent situation is the underutilisation of the existent capacity. This generates cost inefficiency stimulated at the same time by a slow-down in the domestic demand. The results we obtained do not clearly confirm our previous way of thinking about this subject: the more physical capital the more underutilisation and the greater the importance of fixed assets in accounting balance sheets. This could be partially explained by the fact that apart from working with data on a transition economy like the Romanian (high inflation in the period analysed), we face the very common problem of most part of the non-parametric research that is, the impossibility of measuring the real cost frontier. We operate with the empirical cost frontier and for this reason it could be also that the reference units, perform on the frontier because they simply manage better their variable inputs without optimising the level of fixed inputs (we would like to thank to an anonymous referee for the suggestion of an extension of cost inefficiency analysis considering the size of the firms as an influential factor, and the role played by the variable inputs).

\section{Acknowledgements}

Diego Prior received financial support from the Spanish Science and Education Ministry (ref. SEC 99-0771), and Nela Filimon received support from the European Union's Phare ACE Programme 1996.

The authors thank Kristiaan Kerstens, Marcos Estellita Lins, the guest editor, and three anonymous referees for their helpful comments. We are also grateful to the participants in the $24^{\text {th }}$ IAE's Symposium, Barcelona, Spain, 1999; the EURO Working group DEAPM Seminar Day, Copenhagen, Denmark, 1999; the $2^{\text {nd }}$ Oviedo Workshop on Efficiency, Spain, 2000 and in the CEMAPRE Conference, Lisbon, 2000, for their useful comments on earlier versions of the paper.

\section{References}

(1) Andersen, P. \& Petersen, N.C. (1993). A procedure for ranking efficient units in Data Envelopment Analysis. Management Science, 39, 1261-1264.

(2) Berndt, E. \& Hesse, D. (1986). Measuring and assessing capacity utilisation in the manufacturing sectors of nine OECD countries. European Economic Review, 30, 961-989.

(3) Berndt, Ernest R. \& Morrison, C.J. (1981). Capacity utilisation measures: underlying economic theory and an alternative approach. American Economic Review, 71(2), 48-69.

(4) Bresnahan, T.F. \& Ramey, V.A. (1993). Segment shifts and capacity utilisation in the US automobile industry. American Economic Review, 83(2), 213-218. 
(5) Cassels, J.M. (1937). Excess capacity and monopolistic competition. Quarterly Journal of Economics, 51, 426-443.

(6) Data Envelopment Analysis (1992). Warwick Business School.

(7) Djankov, S. (1997). On the determinants of enterprise adjustment: evidence from Moldova. World Bank.

(8) Färe, R. (1984). On the existence of plant capacity. International Economic Review, 25, 209-213.

(9) Färe, R.; Grosskopf, S. \& Kokkelenberg, E.C. (1989). Measuring plant capacity, utilisation and technical change: a non-parametric approach. International Economic Review, 30(3), 655-666.

(10) Färe, R.; Grosskopf, S. \& Valdmanis, V. (1989). Capacity, competition and efficiency in hospitals: a nonparametric approach. Journal of Productivity Analysis, 1, 123-138.

(11) Ferrier, G.; Klinedinst, M. \& Linvill, C. (1998). Static and dynamic productivity among Yugoslav enterprises: components and correlates. Journal of Comparative Economics, 26(4), 805-821.

(12) Filippini, M. (1996). Economies of scale and utilisation in the Swiss electric power distribution industry. Applied Economics, 28(5), 543-550.

(13) Friedman, M. (1963). More on Archibald versus Chicago. Review of Economic Studies, 30, 65-67.

(14) Hickman, B.G. (1964). On a new method for capacity estimation. Journal of the American Statistical Association, 59, 529-549.

(15) Hulten, Charles R. (1986). Productivity change, capacity utilisation, and the source of efficiency growth. Journal of Econometrics, 33(1-2), 31-50.

(16) Hunter, William C. \& Timme, Stephen G. (1995). Core deposits and physical capital: a reexamination of bank scale economies and efficiency with quasi-fixed inputs. Journal of Money Credit and Banking, 27(1), 165-185.

(17) Johansen, L. (1968). Production functions and the concept of capacity. In: Recherches Recentes sur la Function de Production, Collection Economic Mathematique et Econometrie 2.

(18) Klein, L.R. (1960). Some theoretical issues in the measurement of capacity. Econometrics, 28(2), 272-286.

(19) Mercer, L.J. \& Morgan, W.D. (1972). The American automobile industry: investment demand, capacity and capacity utilization, 1921-1940. Journal of Political Economy, 80(6), 1214-1231.

(20) Morrison, C.J. (1985). Primal and dual capacity utilization: An application to productivity measurement in the U.S. automobile industry. Journal of Business and Economic Statistics, 3(4), 312-324.

(21) Nelson, R.A. (1989). On the measurement of capacity utilisation. Journal of Industrial Economics, 37, 273-286. 
(22) Nelson, R. \& Wohar, M.E. (1983). Regulation, scale economies, and productivity in steam-electric generation. International Economic Review, 24(1), 57-79.

(23) Nemoto, J.; Nakasine, Y. \& Madono, S. (1993). Scale economies and over-capitalisation in Japanese electric utilities. International Economic Review, 34(2), 431-440.

(24) Paranko, J. (1996). Cost of free capacity. International Journal of Production Economics, 46-47, 469-476.

(25) Prior, D. (2002). Long- and short-run non-parametric cost frontier efficiency: an application to Spanish savings banks. Journal of Banking \& Finance, forthcoming.

(26) Segerson, K. \& Squires, D. (1990). On the measurement of economic capacity utilisation for multi-product industries. Journal of Econometrics, 44(3), 347-361.

(27) Terrell, K. (1992). Productivity of western and domestic capital in Polish industry. Journal of Comparative Economics, 16, 494-514.

(28) Wilson, P.W. (1995). Detecting influential observations in Data Envelopment Analysis. Journal of Productivity Analysis, 6, 27-45. 